\title{
Value of fractional flow reserve in making decisions about bypass surgery for equivocal left main coronary artery disease
}

G J W Bech, H Droste, N H J Pijls, B De Bruyne, J J R M Bonnier, H R Michels, K H Peels, J J Koolen

\begin{abstract}
Objective-To investigate the value of coronary pressure derived fractional flow reserve (FFR) measurements in supporting decisions about medical or surgical treatment in patients with angiographically equivocal left main coronary artery stenosis.

Design-A two centre prospective single cohort follow up study.

Interventions-FFR of the left main coronary artery was determined in 54 consecutive patients with angiographically equivocal left main coronary artery disease. If FFR was $\geqslant 0.75$, medical treatment was chosen; if FFR was $<0.75$, surgical treatment was chosen.

Main outcome measures-Freedom from death, myocardial infarction, or any coronary revascularisation procedure.

Results-In 24 patients (44\%), FFR was $\geqslant 0.75$ and medical treatment was chosen (medical group). In the remaining 30 patients $(56 \%)$, FFR was $<0.75$ and bypass surgery was performed (surgical group). Mean (SD) follow up was 29 (15) months (range 12-65 months). Survival among patients at three years of follow up was $100 \%$ in the medical group and $97 \%$ in the surgical group. Event-free survival was $76 \%$ in the medical group and $83 \%$ in the surgical group.

Conclusions-FFR supports decision making in equivocal left main coronary artery disease. If FFR is below 0.75, the decision for bypass surgery is supported. If FFR is above 0.75, a conservative approach is justified.
\end{abstract}

(Heart 2001;86:547-552)

Keywords: coronary artery disease; left main coronary artery; fractional flow reserve; coronary artery bypass

The presence of left main coronary artery stenosis may have serious implications and it is often decisive in the choice of surgical versus non-surgical treatment. ${ }^{1}$ However, in clinical practice patients are sometimes encountered with only mild or moderate left main coronary artery stenosis on the angiogram. Although such patients are intuitively at increased risk, it is unclear whether their prognosis will be improved by bypass surgery. On the one hand if there is rupture of an anatomically insignificant left main plaque, the result could be fatal. On the other hand it is conceivable that too early an operation could lead to inappropriate use of available grafts and premature occlusion of either the native vessel or the graft, leaving the future risk of acute occlusion unaffected. ${ }^{2}$ This problem is exacerbated in several ways. First, reliable angiographic assessment and quantitative coronary angiography of a left main coronary artery stenosis is often difficult; second, it is not uncommon for left main coronary artery disease to be suspected but hard to quantify from the angiogram; and third, classical non-invasive tests are often incapable of discriminating between inducible ischaemia caused by the left main coronary artery stenosis itself or by other abnormalities elsewhere in the coronary system. ${ }^{3}$ In case of doubt, surgical treatment is often chosen, encouraged by the widespread and generalised fear of under treating patients.

Fractional flow reserve (FFR), calculated from coronary artery pressure measurement, has been shown to be an accurate and lesion specific index for determining if an intermediate stenosis is functionally significant and responsible for reversible ischaemia. A threshold value of 0.75 clearly distinguishes lesions responsible $(\mathrm{FFR}<0.75)$ or not responsible $(\mathrm{FFR} \geqslant 0.75)$ for reversible ischaemia during exercise. ${ }^{5-7}$ Our aim in this study was to investigate the clinical value of pressure derived FFR measurements in supporting decisions about whether to perform or defer bypass surgery in patients with equivocal left main coronary artery disease.

\section{Methods}

PATIENT POPULATION

All patients were eligible for this study who underwent diagnostic catheterisation in our hospitals between 1994 and 1999 and in whom a left main coronary artery stenosis of $40-60 \%$ was present by visual estimation, or in whom left main coronary artery disease was visible but could not be quantified from the angiogram. Patients were only eligible if no other angiographic abnormalities were present that warranted bypass surgery-for example, if as well as equivocal left main coronary artery stenosis there was also three vessel disease requiring bypass surgery, the patient was not eligible for the study. If on the other hand concomitant disease was present elsewhere in the coronary tree that was suitable for percutaneous transluminal coronary angioplasty (PTCA), the patient was eligible for the study. 
After informed consent had been obtained, coronary artery pressure measurements and calculations of FFR associated with the left main coronary artery stenosis were performed. The decision on whether to perform surgery or to choose conservative treatment was then based upon FFR measurements below or above 0.75 , respectively.

CORONARY CATHETERISATION AND CORONARY PRESSURE MEASUREMENT

After diagnostic catheterisation had been performed, a 6 or 7 French guiding catheter was advanced into the ostium of the left coronary artery. After an intravenous injection of 10000 units of heparin and an intracoronary injection of $200-300 \mu \mathrm{g}$ glyceryl trinitrate, control angiography was done. A pressure monitoring guide wire (Radi Medical Systems, Uppsala, Sweden) was then set to zero, calibrated, and introduced into the guiding catheter. The pressure wire was advanced to the tip of the guiding catheter, and it was verified that the pressure measured by the pressure wire was equal to the pressure measured by the guiding catheter. Next, the pressure wire was advanced further into the left coronary artery until the pressure sensor was located just distal to the left main coronary artery segment. Maximum myocardial hyperaemia was then induced by a continuous infusion of adenosine in a femoral vein at an infusion rate of $140 \mu \mathrm{g} /$ $\mathrm{kg}$ per min for 2-4 minutes. ${ }^{8} 9$ If damping of the aortic pressure signal was observed, the guiding catheter was retrieved from the ostium while leaving the pressure wire distal to the left main coronary artery segment. During maximum hyperaemia, left main coronary artery FFR was calculated from the ratio of the simultaneously recorded mean aortic pressure $\left(\mathrm{P}_{\mathrm{f}}\right)$ and mean coronary artery pressure $\left(\mathrm{P}_{d}\right)\left[\mathrm{FFR}=\mathrm{P}_{d} / \mathrm{P}_{a}\right]$, as described previously. ${ }^{8}$ Measurements were performed with the pressure sensor located in all large branches of the left coronary artery. Some examples of angiograms and pressure recordings of patients in this study are shown in figs 1 and 2 .

If FFR of the left main coronary artery was $\geqslant 0.75$, indicating that in itself the stenosis was unlikely to be physiologically significant, no bypass surgery was performed. If appropriate, PTCA of a concomitant lesion elsewhere in the coronary tree was done and medical treatment was continued with aspirin and statins if indicated (medical group). If FFR of the left main coronary artery was $<0.75$, indicating that the lesion had physiological significance and that the left main coronary artery stenosis was most probably associated with inducible ischaemia, coronary artery bypass grafting (CABG) was undertaken (surgical group).

Quantitative coronary arteriographic analysis was done on control cineangiograms obtained just before the intracoronary pressure measurements.

FOLLOW UP AND CLINICAL EVENTS

All patients were closely followed for an average of 2.5 years (range $12-63$ months), with clinical visits at least once a year. Data on angina

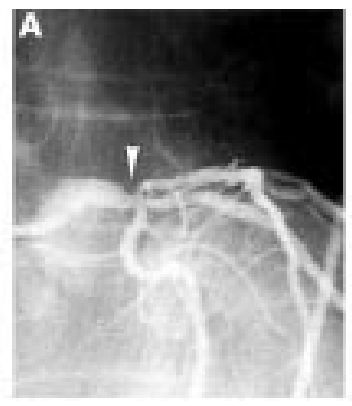

B

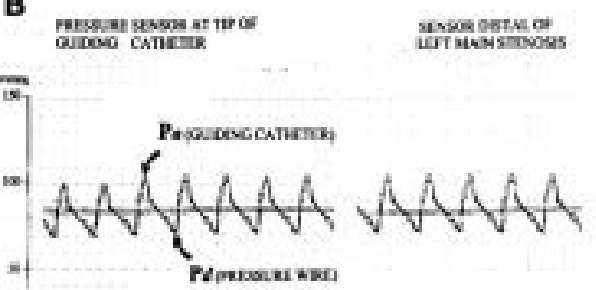

C

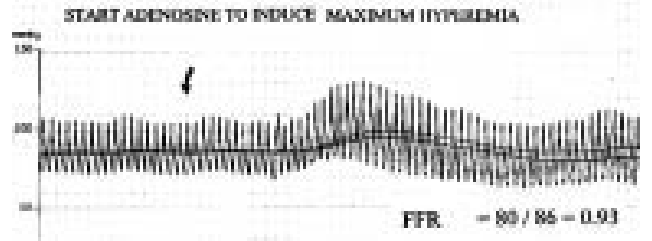

D

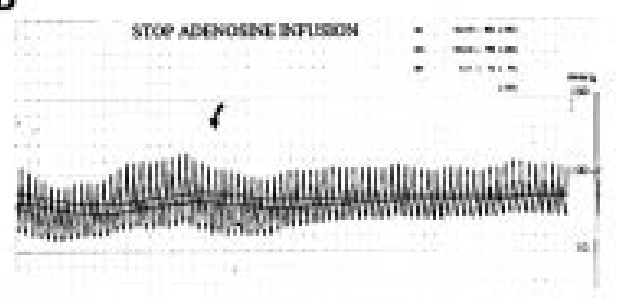

Figure 1 (A) Coronary angiogram in the right anterior oblique projection of a 58 year old man with anginal complaints, a reversible defect on exercise perfusion scintigraphy in the anterior wall, a $40 \%$ stenosis (arrow) at the transition of the distal left main coronary artery (LM), and an $80 \%$ stenosis of the proximal left anterior descending coronary artery (LAD). The dilemma was to decide whether the ischaemia was caused by the proximal $L A D$ disease only or also by the left main stenosis, and consequently if bypass surgery should be performed or only percutaneous transluminal coronary angioplasty (PTCA) of the proximal $L A D$. (B) Paper speed is $25 \mathrm{~mm} / \mathrm{s}$. The pressure wire is advanced until the sensor is close to the tip of the guiding catheter to confirm that two identical signals are obtained. $P_{a}$ is the pressure as measured by the guiding catheter and $P_{\text {a }}$ the pressure as measured by the pressure wire. The pressure wire is then advanced across the LM stenosis into the large intermediate branch and no gradient is observed at rest. (C) Paper speed is $5 \mathrm{~mm} / \mathrm{s}$. About 20 seconds after the start of the intravenous adenosine infusion $(140 \mu \mathrm{g} / \mathrm{kg} / \mathrm{min})$ a pressure gradient gradually develops (arrow) and at steady state, maximum coronary hyperaemic myocardial fractional flow reserve is calculated by the ratio between $P_{d}$ and $P_{a}$ [80/86 = 0.93], indicating that this left main lesion in itself was not significant from a functional point of view.

(D) About 30 seconds after cessation of adenosine infusion the pressure gradient disappears and returns to baseline. In this patient bypass surgery was deferred and he underwent PTCA of the proximal left anterior descending stenosis only. FFR of the LAD was 0.63 before and 0.94 after PTCA.

frequency and drug use were obtained at all follow up visits. Major adverse events were mutually exclusive and defined in the following 


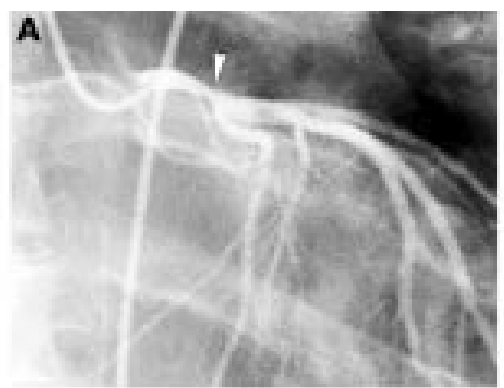

B

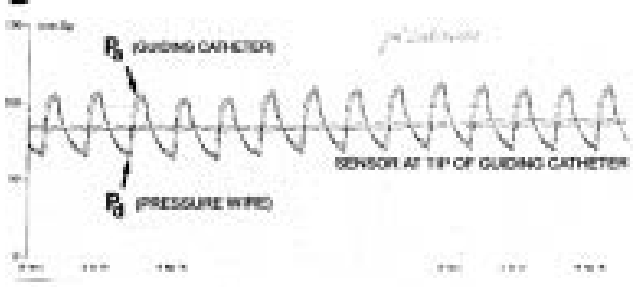

C

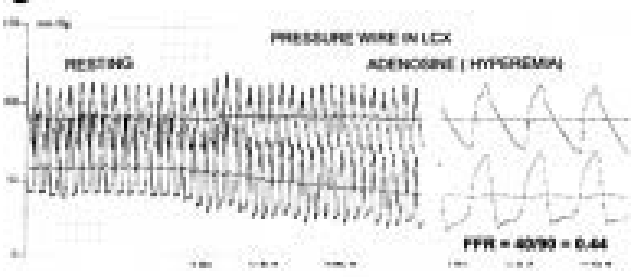

D

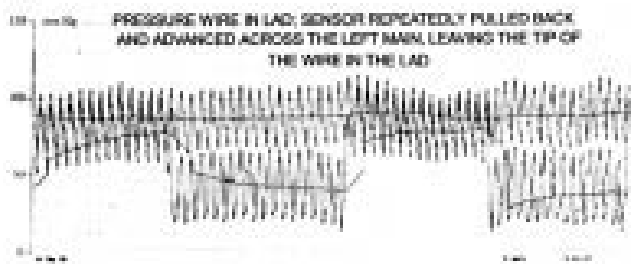

Figure 2 (A) Coronary angiogram in the right anterior oblique projection from a 36 year old man who experienced an anterior wall myocardial infarct, successfully treated by thrombolysis. At angiography only a 40\% stenosis (arrow) of the distal left main coronary artery (LM) was visible, and there was mild hypokinesia of the anterior wall segments. Perfusion scintigraphy performed several weeks later was negative. The dilemma was whether to perform bypass surgery or to leave this lesion untreated. (B) $A$ pressure wire is advanced to the tip of the coronary catheter, and equal pressures are registered at that position by the guiding catheter $\left(P_{\alpha}\right)$ and the pressure sensor $\left(P_{d}\right)$. (C) The pressure wire is advanced across the left main stenosis into the left circumflex coronary artery and a large gradient is observed at rest. After start of intravenous adenosine infusion (140 $\mu \mathrm{g} / \mathrm{kg} / \mathrm{min})$, this gradient gradually further increases and at steady state maximum coronary hyperaemic myocardial fractional flow reserve is calculated by the ratio between $P$ and $P[40 / 90=0.44]$, indicating that this left main lesion is physiologically highly significant. (D) Shows how the wire is positioned in the left anterior descending coronary artery and slowly withdrawn and advanced across the left main stenosis. Because the pressure sensor is located at $3 \mathrm{~cm}$ from the tip of the wire, this pull-back/push-up procedure can be performed repeatedly under fluoroscopy. It confirms the presence and exact location of a stenosis. This patient was treated by bypass surgery.

ranking order: death from any cause; myocardial infarction; coronary bypass surgery or redo surgery; coronary angioplasty. Angiographic follow up was only performed in case of recurrent complaints or coronary events.
STATISTICS

Continuous data are reported as mean (SD). Differences within and between subgroups were tested by use of paired or unpaired Student's $t$ tests. Categorical differences between subgroups were tested for using Fisher's exact test or the $\chi^{2}$ test. Patient survival curves and curves for freedom of death or major adverse cardiac events were constructed according to Kaplan and Meier. ${ }^{10}$ A probability value of $\mathrm{p}<0.05$ was considered significant. All tests were two tailed.

\section{Results}

BASELINE CHARACTERISTICS AND PROCEDURAL OUTCOMES

Table 1 shows baseline clinical and angiographic data of the two groups. Except for smoking and a family history of coronary heart disease, no significant differences were present between the groups. No complications occurred during catheterisation or coronary pressure measurement. Pressure recordings of two patients are shown in figs 1 and 2 .

In 24 of the 54 patients, FFR of the left main coronary artery stenosis was 0.75 or more, making inducible ischaemia from left main coronary artery stenosis highly unlikely, so bypass surgery was not performed (medical group). In this group 16 patients were treated with drugs alone, seven underwent PTCA for a concomitant lesion, and one underwent aortic valve replacement without bypass surgery. In the remaining 30 patients FFR of the left main coronary artery stenosis was below 0.75 , indicating that the lesion was haemodynamically significant. CABG was performed in these patients within a few days (surgical group).

Although baseline left main coronary artery per cent diameter stenosis was similar between the medical and surgical groups, the mean reference diameter and minimum lumen diameter were significantly larger in the medical group, but with substantial overlap (table 1; fig 3).

FOLLOW UP

Follow up was obtained in all patients. Mean (SD) follow up was 29 (15) months (range 12-63 months). Events during follow up are detailed in table 2 .

In the medical group, five patients experienced an event during follow up - after 3, 4, 16, 28 , and 42 months, respectively. In all of these, chest pain developed or worsened, accompanied by a positive exercise test in four cases. In two cases, progression of left main coronary artery disease was present, both angiographically and physiologically. These two patients both underwent bypass surgery. In three patients, progression of disease in other coronary branches was observed, requiring bypass surgery in one and PTCA in two.

In the surgical group five patients also experienced an event during follow up: one patient died 29 days after surgery because of respiratory failure from acute respiratory distress syndrome and pneumonia; in one patient a large anterior wall myocardial infarct occurred perioperatively; in the three other patients early 
Table 1 Baseline clinical and angiographic data

\begin{tabular}{|c|c|c|}
\hline & $\begin{array}{l}\text { Medical group, } \\
F F R \geqslant 0.75 \\
(n=24)\end{array}$ & $\begin{array}{l}\text { Surgical group, } \\
F F R<0.75 \\
(n=30)\end{array}$ \\
\hline Male & $18(75 \%)$ & $26(87 \%)$ \\
\hline Age (years) & $60(9)$ & $63(9)$ \\
\hline \multicolumn{3}{|l|}{ Risk factors } \\
\hline Hypertension & $4(17 \%)$ & $9(30 \%)$ \\
\hline Diabetes & $8(33 \%)$ & $6(20 \%)$ \\
\hline Raised cholesterol & $8(33 \%)$ & $14(47 \%)$ \\
\hline Smoking ${ }^{\star}$ & $7(29 \%)$ & $19(63 \%)$ \\
\hline Family history* & $4(17 \%)$ & $16(53 \%)$ \\
\hline Previous PTCA & $2(8 \%)$ & $4(13 \%)$ \\
\hline Previous infarction & $8(33 \%)$ & $5(16 \%)$ \\
\hline CCS class & $2.8(1.0)$ & $3.4(0.9)$ \\
\hline Stress test performed & $13(54 \%)$ & $10(33 \%)$ \\
\hline Positive/negative/inconclusive & $8 / 1 / 4$ & $7 / 1 / 2$ \\
\hline Ejection fraction $(\%)$ & $55(8)$ & $57(6)$ \\
\hline \multicolumn{3}{|l|}{ Additional disease } \\
\hline One/two vessel disease & $10 / 6$ & $10 / 13$ \\
\hline Duration of follow up (months) & $28(15)$ & $29(14)$ \\
\hline \multicolumn{3}{|l|}{ Angiographic data } \\
\hline Reference diameter (mm) & $4.06(0.67)$ & $3.45(0.59)^{\star}$ \\
\hline Minimum lumen diameter (mm) & $2.35(0.46)$ & $1.95(0.39)^{\star}$ \\
\hline Diameter stenosis (\%) & $42(9)$ & $43(10)$ \\
\hline \multicolumn{3}{|l|}{ Pressure data } \\
\hline $\mathrm{P}_{a}(\mathrm{~mm} \mathrm{Hg})$ & $90(13)$ & $95(18)$ \\
\hline $\mathrm{P}_{d}(\mathrm{~mm} \mathrm{Hg})$ & $81(10)$ & $63(14)^{\star}$ \\
\hline Fractional flow reserve & $0.90(0.06)$ & $0.67(0.09)^{\star}$ \\
\hline
\end{tabular}

Values are $\mathrm{n}(\%)$ or mean (SD).

${ }^{\star} \mathrm{p}<0.05$.

CCS, Canadian Cardiovascular Society; FFR, fractional flow reserve; $\mathrm{P}_{t}$, aortic pressure; $\mathrm{P}_{d}$, mean hyperaemic coronary pressure just distal to the left main coronary artery; PTCA, percutaneous transluminal coronary angioplasty.

redo thoracotomy was necessary in the first hours after surgery, twice because of recurrent ischaemia (treated by additional placement of a saphenous vein graft on the left anterior descending coronary artery), and once because of intractable mitral valve regurgitation treated by mitral valve replacement. In none of the patients in the surgical group did any event occur during the remaining follow up period.

Canadian Cardiovascular Society (CCS) angina class decreased from (mean (SD)) 2.8 (1.0) at baseline to $1.6(0.7)$ at the last follow up visit in the medical group ( $\mathrm{p}<0.001)$, and from $3.4(0.9)$ to $1.5(0.8)$ in the surgical group B ( $p<0.0001)$. At follow up, 43 of 52 patients were in CCS class $\leqslant 2$. In the medical group the number of antianginal drugs used decreased from $2.1(1.2)$ to $1.5(1.1)(p=0.01)$, and in the surgical group from 2.1 (1.5) to 1.1 $(0.9)(\mathrm{p}<0.0001)$.

SURVIVAL AND CARDIAC EVENT-FREE SURVIVAL

The Kaplan-Meier estimated percentage survival (SEM) at three years was $100(0) \%$ in the medical group and 97 (3)\% in the surgical group. Event-free survival (SEM) at three years was 76 (11)\% and 83 (7)\%, respectively. Events in the medical group were equally distributed over time, whereas in the surgical group all events occurred early and were related to the bypass operation itself (table 2; fig 4).
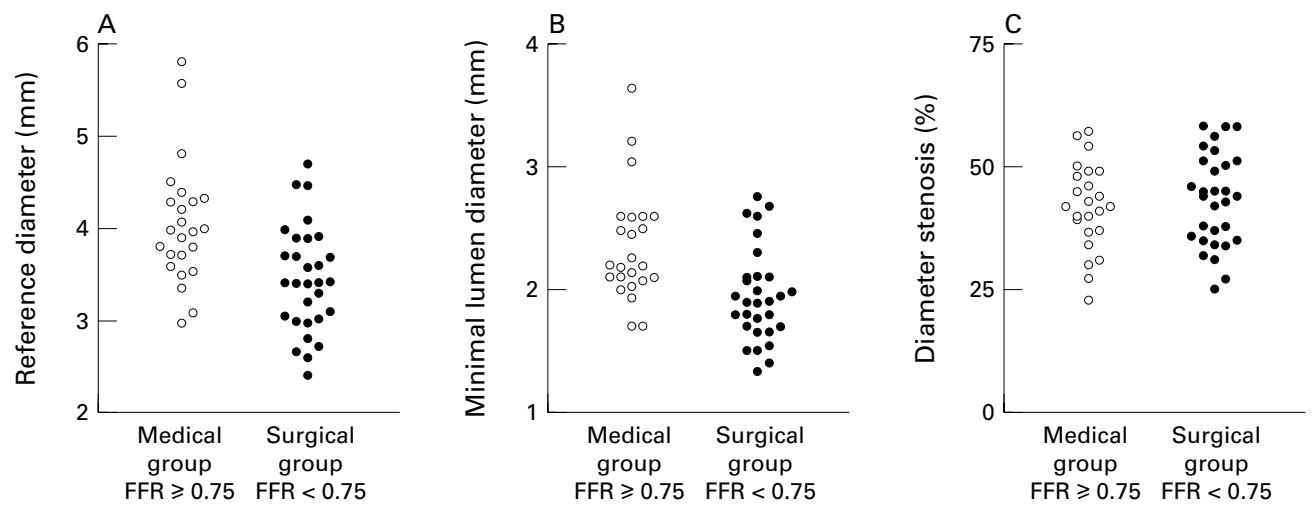

Figure 3 Relation between reference diameter, minimum lumen diameter, and per cent diameter stenosis versus myocardial fractional flow reserve. Empty circles represent the 24 patients in the medical group with left main coronary artery FFR $\geqslant$ 0.75 ; filled circles represent the 30 patients in the surgical group with left main coronary artery FFR $<0.75$.

Table 2 Patients with an event during follow up

\begin{tabular}{|c|c|c|c|c|c|c|c|}
\hline $\begin{array}{l}\text { Patient/ } \\
\text { sex }\end{array}$ & $\begin{array}{l}\text { Age } \\
\text { (years) }\end{array}$ & $\begin{array}{l}R D \\
(m m)\end{array}$ & $\begin{array}{l}M L D \\
(m m)\end{array}$ & $\begin{array}{l}D S \\
(\%)\end{array}$ & $\begin{array}{l}F F R \\
L M\end{array}$ & Initial treatment & Event, treatment of event (days to event) \\
\hline \multicolumn{8}{|c|}{ Medical group $(F F R \geqslant 0.75)$} \\
\hline $1 / \mathrm{M}$ & 61 & 4.30 & 2.61 & 40 & 0.85 & Medical treatment & $\begin{array}{l}\text { Exercise test positive, CAG, disease progression proximal } \\
\text { LAD, PTCA ( } 82)\end{array}$ \\
\hline $2 / \mathrm{F}$ & 70 & 4.01 & 2.10 & 48 & 0.96 & PTCA LAD & CAG, restenosis LAD, re-do PTCA (118) \\
\hline $3 / \mathrm{M}$ & 42 & 4.51 & 1.93 & 57 & 0.95 & Medical treatment & $\begin{array}{l}\text { Exercise test positive, CAG, disease progression LM, } \\
\text { CABG (482) }\end{array}$ \\
\hline $4 / \mathrm{F}$ & 49 & 2.98 & 2.18 & 27 & 0.95 & Medical treatment & $\begin{array}{l}\text { Exercise test positive, CAG, disease progression LM, } \\
\text { CABG (845) }\end{array}$ \\
\hline $5 / M$ & 68 & 5.57 & 2.45 & 56 & 0.96 & PTCA LCX & $\begin{array}{l}\text { Exercise test positive, CAG, new stenosis LAD and RCA, } \\
\text { CABG (1293) }\end{array}$ \\
\hline \multicolumn{8}{|c|}{ Surgical group $($ FFR $<0.75)$} \\
\hline $6 / \mathrm{F}$ & 70 & 4.48 & 2.76 & 38 & 0.50 & LITA LAD & Postoperative ischaemia, redo thoracotomy, SVG LAD (0) \\
\hline $7 / \mathrm{M}$ & 61 & 2.41 & 1.80 & 25 & 0.62 & Left main reconstruction, SVG RCA & Postoperative ischaemia, anterior myocardial infarction (0) \\
\hline $8 / \mathrm{M}$ & 75 & 3.89 & 2.68 & 31 & 0.72 & LITA LAD, SVG RCA, SVG LCx, AVR & Postoperative mitral regurgitation, valve replacement $(0)$ \\
\hline 9/M & 66 & 3.02 & 1.54 & 49 & 0.73 & LITA LAD & Postoperative ischaemia, redo thoracotomy, SVG LAD (0) \\
\hline $10 / \mathrm{M}$ & 81 & 3.92 & 1.65 & 58 & 0.63 & LITA LAD, SVG jump D1-LCx-RCA & Postoperative ARDS and pneumonia, death (29) \\
\hline
\end{tabular}

ARDS, acute respiratory distress syndrome; AVR, aortic valve replacement; CABG, coronary artery bypass grafting; CAG, coronary angiography; DS, diameter stenosis; D1, first diagonal branch; F, female; FFR, fractional flow reserve; LAD, left anterior descending coronary artery; LCx, left circumflex coronary artery; LITA, left interthoracic artery; M, male; MLD, minimum lumen diameter; PTCA, percutaneous transluminal coronary angioplasty; RCA, right coronary artery; RD, reference diameter; SVG, saphenous vein graft. 
A Freedom from death during follow up

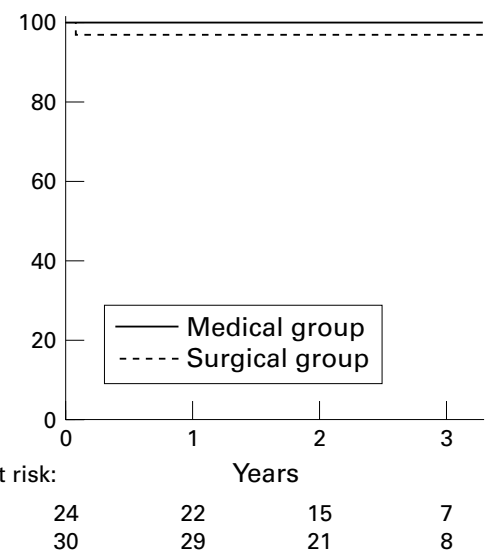

B Freedom from any event during follow up

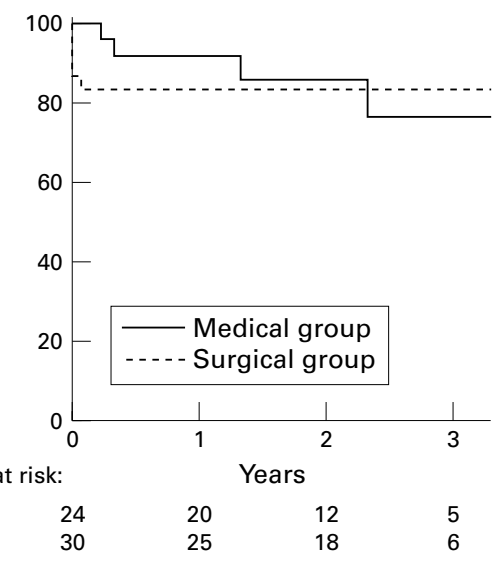

Figure 4 Estimated survival and event-free survival curves after three years of follow up (Kaplan-Meier) for the two study groups. The medical group consisted of 24 patients with an equivocal left main coronary artery stenosis in whom bypass surgery was deferred on the basis of a left main coronary artery FFR of $\geqslant 0.75$. The surgical group consisted of 30 patients with an equivocal left main coronary artery stenosis in whom bypass surgery was performed on the basis of a left main coronary artery FFR of $<0.75$. Numbers below the $x$ axis represent patients at risk at one, two, and three years of follow up.

\section{Discussion}

Our study shows that in patients with mild or moderate left main coronary artery disease, measurement of FFR is useful in making decisions about whether or not to proceed to bypass surgery.

In patients with significant left main coronary artery stenosis, coronary bypass surgery prolongs life. ${ }^{11-13}$ Thus it is generally accepted that a bypass operation should be performed in patients with left main coronary artery stenosis which is significant at angiography, or unequivocally associated with reversible ischaemia on non-invasive stress testing.

In patients with equivocal left main coronary artery stenosis the best treatment is less obvious. On the one hand it is clear that an insignificant plaque can, if it ruptures, have dramatic consequences; on the other hand, early surgery could lead to the inappropriate use of available graft material and premature occlusion of either the native vessel or the graft, leaving the future risk of acute occlusion unaffected. ${ }^{14}$ In the case of equivocal left main coronary artery disease, this clinical dilemma is aggravated for three reasons. First, reliable angiographic assessment and quantitative coronary angiography are often difficult to perform in left main coronary artery stenosis. ${ }^{15}$ Second, the classical non-invasive tests to document reversible ischaemia often cannot differentiate between ischaemia caused by the left main coronary artery itself or that accompanying other stenoses elsewhere in the coronary tree. ${ }^{16}{ }^{17}$ Finally, bypass surgery for left main coronary artery disease is not without risk in itself. ${ }^{18}$

When there is doubt about the need for left main coronary artery revascularisation, coronary pressure derived FFR can be used as a reliable and lesion specific index to document the presence of reversible ischaemia caused by the left main coronary artery stenosis. Our purpose in this study was to evaluate the additional value of this physiological index in making a decision on whether to perform bypass surgery straight away or to defer it.
Our study shows that in those patients with an intermediate left main coronary artery stenosis (40-60\%), about half the stenoses $(56 \%)$ can be considered physiologically significant, with an FFR value of $<0.75$, and half $(44 \%)$ cannot. In the first group, CABG was performed, on the basis of earlier studies; in the second group no surgery was performed and a medical approach was chosen. ${ }^{171219}$ This strategy was accompanied by an excellent survival and freedom from events for up to three years of follow up, and importantly - although both groups were comparable in terms of percentage diameter stenosis-the medical group with an FFR of 0.75 or above had a similar outcome to the surgical group, with an FFR below 0.75. Furthermore, the events in the medical group were less serious (no deaths and no myocardial infarction), they were equally distributed over time, and CABG was still necessary in three patients in the following five years. All events in the surgical group occurred early.

At follow up, average CCS class decreased significantly in both groups. However, this improvement was largest in the patients with an FFR below 0.75 , indicating that their complaints were associated with the left main coronary artery lesion and that subsequent CABG was in fact justified.

Another interesting observation is that, although average stenosis severity was equal in the two groups (table 1), the patients with an FFR of $<0.75$ had a smaller reference diameter by quantitative coronary angiography and accordingly a smaller minimum lumen diameter (fig 3). It is likely that in those patients diffuse left main coronary artery disease was present, which was not detected by lumenography. This phenomenon of diffuse left main coronary artery disease is well known from intravascular ultrasound (IVUS) studies, which have also shown that occult left main artery disease may be more common than is generally appreciated. These studies have shown the additional value of IVUS in patients with intermediate left main stenosis, ${ }^{20-22}$ though 
comparative studies of IVUS and FFR have not been performed so far.

Despite the lower mean reference diameter and minimum lumen diameter in patients with functionally significant stenoses, angiography was not capable of distinguishing in individual patients which stenoses were functionally significant and which were not (fig 3).

There have been few prospective studies on left main coronary artery stenosis, and in case of doubt most clinicians elect to do bypass surgery. ${ }^{11}{ }^{12}$ In the present prospective nonrandomised study, all consecutive patients with equivocal left main coronary artery disease in whom such a dilemma was present were included. The decision to operate or not was based entirely on the FFR. Therefore we believe that our study is representative of those patients with equivocal left main coronary artery disease and that it has direct clinical implications for decision making.

We have shown earlier that in patients with intermediate stenosis it is in general safe to defer surgical intervention if the stenosis has no physiological significance-that is, if it does not cause reversible ischaemia ${ }^{19}$; this can now be extended to angiographic stenosis of the intermediate left main coronary artery. Finally, as with all other non-significant stenoses, there is no evidence that affected patients are at a higher risk of events than persons without any coronary artery disease. However, the issue addressed here is that the prognosis will probably not be improved by surgery unless the stenosis is physiologically significant.

\section{LIMITATIONS}

As this study was non-randomised, it is impossible to determine what the event rates would have been if CABG had been performed in patients with an FFR of $\geqslant 0.75$, or not performed in patients with an FFR of $<0.75$. Thus we do not have any evidence that patients with angiographically equivocal left main coronary artery stenosis and an FFR of $<0.75$ would definitely have benefited from CABG, as opposed to medical treatment alone. However, it has been well documented that the presence and extent of inducible ischaemia are the most important prognostic factors in coronary artery disease, so it was considered unethical not to perform surgery in patients in whom inducible ischaemia was present, and in whom it could be assumed that there was a relation between the ischaemia and the left main coronary artery stenosis. ${ }^{23}$

Routine follow up angiography was not scheduled in this study to avoid bias in the decision making process.

\section{CONCLUSIONS}

Our study shows that in patients with suspected equivocal left main coronary artery disease, intracoronary pressure measurements and calculations of the FFR are feasible and help in decisions about surgical versus medical treatment. In patients with an FFR of the left main coronary artery of $\geqslant 0.75$, CABG may be deferred, and inappropriate use of graft material is avoided. A medical approach with regular follow up is appropriate in these patients. In patients with an FFR of the left main coronary artery of $<0.75$, the equivocal left main coronary artery stenosis has functional significance and so CABG is justified. This study underlines the inability of angiography and quantitative coronary angiography to discriminate between physiologically significant and non-significant equivocal left main coronary artery lesions.

1 Caracciolo EA, Davis KB, Sopko G, et al, for the CASS Investigators. Comparison of surgical and medical group survival in patients with left main coronary artery disease. Circulation 1995;91:2325-34.

2 Lust RM, Zeri RS, Spence PA, et al. Effect of chronic native flow competition on internal thoracic artery grafts. Ann Thorac Surg 1994;57:45-50.

3 Isner JM, Kishel J, Kent KM, et al. Accuracy of angiographic determination of left main coronary arterial narrowing. Circulation 1981;63:1056-64.

4 Cameron A, Kemp HG, Fisher LD, et al. Left main coronary artery stenosis: angiographic determination. Circulation 1983;3:484-9.

5 Pijls NHJ, Van Gelder B, Van der Voort P, et al. Fractional flow reserve: a useful index to evaluate the influence of an epicardial coronary stenosis on myocardial blood flow. Circulation 1995;92:3183-93.

6 De Bruyne B, Bartunek J, Sys SU, et al. Relation between myocardial fractional flow reserve calculated from coronary pressure measurements and exercise-induced myocardial ischemia. Circulation 1995;92:93-6.

7 Pijls NHJ, De Bruyne B, Peels K, et al. Measurement of fractional flow reserve to assess the functional severity of coronary-artery stenoses. N Engl f Med 1996; 334:1703-8.

8 Van der Voort P, Van Hagen E, Hendrix G, et al. Comparison of intravenous adenosine to intracoronary papaverine for calculation of pressure-derived fractional flow reserve. Cathet Cardiovasc Diagn 1996;39:120-5.

9 Kern MJ, Deligonul U, Tatineni S, et al. Intravenous adenosine: continuous infusion and low dose bolus administration for determination of coronary vasodilator reserve in patients with and without coronary artery disease. $\mathcal{F} \mathrm{Am}$ Coll Cardiol 1991;18:718-29.

10 Kaplan EL, Meier P. Nonparametric estimation of incomplete observations. $\dot{f}$ Am Stat Assoc 1958;53:457-81.

plete observations. F Am Stat Assoc 1958;53:457-81.
11 Takaro T, Peduzzi P, Detre KM, et al. Survival in subgroups of patients with left main coronary artery disease: Veterans of patients with left main coronary artery disease: Veterans arterial occlusive disease. Circulation 1982;66:14-21.

12 European Coronary Surgery. Study Group. Long-term results of prospective randomized study of coronary artery bypass surgery in stable angina pectoris. Lancet 1982;ii: $1173-80$.

13 Mock MB, Killip T. Effect of coronary bypass surgery on survival patterns in subsets of patients with left main coronary artery disease: report of the collaborative study in coronary artery surgery (CASS). Am $\mathcal{F}$ Cardiol 1981;48: $765-77$.

14 Hashimoto $\mathrm{H}$, Isshiki $\mathrm{T}$, Ikari Y, et al. Effects of competitive blood flow on arterial graft patency and diameter. Medium-term postoperative follow-up. $\mathcal{F}$ Thorac Cardiovasc Surg 1996;111:399-407.

15 Nishimura RA, Higano ST, Holmes DR. Use of intracoronary ultrasound imaging for assessing left main coronary nary ultrasound imaging for assessing left main

16 Janosi A, Vertes A. Exercise testing and left main coronary artery stenosis: can patients with left main disease be idenified? Chest 1991;100:227-9.

17 Gibbons RJ, Fyke FE, Brown ML, et al. Comparison of exercise performance in left main and three vessel coronary artery disease. Cathet Cardiovasc Diagn 1991;22:14-20.

18 Chaitman BR, Rogers WJ, Davis K, et al. Operative risk factors in patients with left main coronary artery disease. $N$ Engl f Med 1980;303:953-7.

19 Bech GJW, De Bruyne B, Bonnier HJRM, et al. Long-term follow-up after deferral of percutaneous transluminal coronary angioplasty of intermediate stenosis on the basis of coronary pressure measurement. $7 \mathrm{Am}$ Coll Cardiol 1998;31:841-7.

20 Erbel R, Ge J, Bockisch P, et al. Value of intracoronary ultrasound and Doppler in the differentation of angiographically normal coronary arteries: a prospective study in

patients with angina pectoris. Eur Heart f 1996;17:880-9. sound (IVUS) examination reverses therapeutic decision from percutaneous intervention to a surgical approach in from percutaneous intervention to a surgical approach in patients with alterations of the
diovasc Surg 1998;46:281-4.

22 Johnston PW, Fort S, Cohen EA. Noncritical disease of the left main coronary artery: limitations of angiography and the role of intravascular ultrasound. Can f Cardiol 1999;15: 297-302.

23 Beller GA, Zaret BL. Contributions of nuclear cardiology to diagnosis and prognosis of patients with coronary artery disease. Circulation 2000;101:1465-78. 